\title{
Correction to: Compositional design and Taguchi optimization of hardness properties in silicone-based ocular lenses
}

\author{
Mohammad Hanifeh ${ }^{1} \cdot$ Mojgan Zandi ${ }^{1}$. Parvin Shokrollahi ${ }^{1} \cdot$ Mohammad Atai $^{2}$ - Ebrahim Gafar-Zadeh ${ }^{3}$. \\ Fahimeh Askari ${ }^{1}$
}

Published online: 23 January 2018

(c) The Author(s) 2018. This article is an open access publication

\section{Correction to: Prog Biomater (2017) 6:67-74 https://doi.org/10.1007/s40204-017-0065-y}

The original version of this article unfortunately contained a mistake: The spelling of the Ebrahim Gafar-Zadehs' name was incorrect. The corrected name is given above.

Open Access This article is distributed under the terms of the Creative Commons Attribution 4.0 International License (http://creativecommons.org/licenses/by/4.0/), which permits unrestricted use, distribution, and reproduction in any medium, provided you give appropriate credit to the original author(s) and the source, provide a link to the Creative Commons license, and indicate if changes were made.

The original article can be found online at https://doi.org/10.1007/ s40204-017-0065-y.

Mojgan Zandi

m.zandi@ippi.ac.ir

1 Biomaterials Department, Iran Polymer and Petrochemical Institute, Pazhoohesh Blvd., Tehran-Karaj Hwy,

Tehran 1497713115, Iran

2 Science Department, Iran Polymer and Petrochemical Institute, Pazhoohesh Blvd., Tehran-Karaj Hwy, Tehran 1497713115, Iran

3 Lassonde School of Engineering, York University, 4700 Keele Street, 11 Arboretum Ln, Toronto, ON M3J 1P3, Canada 